\title{
SENTENCIAS TRASCENDENTALES DE LA CORTE SUPREMA DE LOS ESTADOS UNIDOS. PASOS HACIA LA IGUALDAD DEL MATRIMONIO PARA PAREJAS DEL MISMO SEXO Transcendent judgments of the Supreme Court of the United States. Steps TOWARD MARRIage EQUALITy For \\ SAME-SEX COUPLES \\ ArrêtS Fondamentals de la COUR SUPRÊME DES ÉtATS-Unis. ÉTAPES VERS L'ÉGALITÉ DU MARIAGE POUR LES COUPLES DU MÊME SEXE
}

Julie A. Davies*

\section{INTRODUCCIÓN}

El 26 de junio de 2013, la Corte Suprema de los Estados Unidos publicó dos sentencias muy importantes en relación al matrimonio entre personas del mismo sexo: U.S. v. Windsor ${ }^{1}$ y Hollingsworth v. Perry ${ }^{2}$. La primera (U.S. v. Windsor), termina la discriminación del gobierno federal contra las parejas del mismo sexo que ya han contraído matrimonio en Estados Unidos ${ }^{3}$. La segunda (Hollingsworth $v$. Perry), declaró que la Corte Suprema, a diferencia de otros tribunales de apelación ${ }^{4}$, no tiene jurisdiction sobre este pleito ${ }^{5}$. Ambas sentencias, esperadas y temidas a la vez, no ponen fin a las demandas de igualdad ante la ley para las parejas del mismo sexo que desean casarse. Esta cuestión va a seguir debatiéndose en cada estado $^{6}$. Pero Windsor y Hollingsworth ponen de manifiesto cómo los ministros

\footnotetext{
* Juris Doctor, UCLA Law School, 1981; B.A. UCLA 1978. Profesora de Derecho, University of the Pacific, McGeorge School of Law, Sacramento, California 95817. Correo electrónico: jdavies@pacific.edu.

Agradezco al Lic. Héctor de Ávila, Sacramento, California, por su ayuda con el español legal, y al Profesor Larry Levine, mi colega en la universidad y un experto en el derecho de orientación sexual. Gracias también a Andrea Athenas y Vallerye Mosquera, estudiantes bilingües en nuestra facultad, por su ayuda con la investigación y el español.

${ }^{1}$ United States v. Windsor, 133 S. Ct. 2675 (2013).

${ }^{2}$ Hollingsworth v. Perry, 133 S. Ct. 2652 (2013).

3 Véase el texto que acompaña notas 43-44, infra.

452 Cal.4th 1116 (2011), 591 F.3d 1147 (2009).

5 Véase el texto que acompaña notas 65-67, infra.

${ }^{6}$ Las partes interesadas van a luchar para cambiar las leyes de varios estados que prohíben el matrimonio de parejas del mismo sexo. Una manera de luchar será empezar un pleito con el propósito de regresar al Tribunal Supremo y resolver las cuestiones constitucionales.
} 
podrían analizar las cuestiones constitucionales con respecto a estos asuntos si un caso vuelve a la Corte Suprema, lo cual parece inevitable.

Antes de explicar las decisiones, U.S. v. Windsor y Hollingsworth v. Perry, es importante entender el contexto político, histórico y legal de los derechos gay, y su desarrollo en los últimos años. Aunque Estados Unidos no fue uno de los primeros países en crear un ambiente abierto para la gente que se identifica homosexual o lesbiana, poco a poco este grupo ha logrado una buena acogida general en algunos estados ${ }^{7}$. Sin embargo, debido a que una gran parte de la población continúa siendo muy conservadora y obediente a los mandatos de los líderes religiosos, también hay regiones del país, incluso estados enteros, donde se rechaza la idea de incluir a homosexuales y lesbianas como sujetos de derechos humanos. Este rechazo ha sido evidente en varias leyes federales y en las leyes de muchos estados.

A nivel federal, por ejemplo, las leyes de los Estados Unidos no prohíben la discriminación contra los homosexuales ${ }^{8}$ en el empleo 9 . Una empresa no podría despedir sin causa a una mujer por ser mujer, o a un latino por ser latino ${ }^{10}$, pero podría poner fin al contrato de trabajo de una lesbiana sin consecuencias, a menos que haya una ley contra la discriminación en el estado específico donde resida ${ }^{11}$. Hasta el año pasado, existía una política de discriminación contra los homosexuales

\footnotetext{
${ }^{7}$ Desde los años setenta, la opinión sobre la homosexualidad en los EE.UU. empezó a ser más liberal, a pesar de la tendencia conservadora en los años ochenta. En los años noventa se vuelve a ver un aumento en la aceptación de la homosexualidad, como también un alza en el apoyo de las libertades civiles de los homosexuales. Loftus, Jeni (2001). "America’s Liberalization in Attitudes toward Homosexuality, 1973 to 1998”. 66 Am. Sociological Rev. 778, Oct.

${ }^{8} \mathrm{Al}$ usar la palabra "homosexual", me refiero a hombres y mujeres que identifican su orientación sexual hacia personas de su mismo sexo. El término gay es sinónimo.

${ }^{9}$ Bajo el Titulo VII de la Ley de Derechos Civiles (Civil Rights Act) de 1964, un empleador no puede discriminar a un postulante o empleado en base de raza, nacionalidad, color, religión o sexo. 42 U.S.C. \$2000e (2012). "Overall, nineteen state and federal courts in twenty-six different judicial opinions have concluded that $L G B$ individuals have faced a history of discrimination as a result of their sexual orientation. Other branches of the federal government have also acknowledged that members of the LGB community face widespread workplace discrimination”. SHAPIRO, Jason E. (2012-2013). Employee Benefits Law: The Hidden Gap Enabling Sexual Orientation Discrimination in Employment.19 Cardozo J.L. \& Gender 516, 517. La Employment NonDiscrimination Act (ENDA) suministraría la protección para aquellos quienes sufrieron discriminación en base de su orientación sexual en el lugar de empleo y, después de dos décadas, recientemente acaba de ser aprobada en el Senado. Trottman, Melanie (2013). "Senate Panel Passes LGBT Nondiscrimination Bill”. W.S.J., July 10. Disponible en: <http://blogs.wsj.com/washwire/2013/07/10/senate-panel-passeslgbt-nondiscrimination-bill>.

${ }^{10}$ Claro que existe la posibilidad de que los latinos sufran discriminación a causa del estatus migratorio, o aún sospechas de que carecen de estatus. Pero es un problema distinto al problema de discriminación en base al origen nacional o la raza de una persona.

${ }^{11}$ En efecto, hay dos niveles de leyes, federales y estatales. Si las leyes federales mandan no-discriminación, los estados tienen que seguir el mandato. Pero si las leyes federales no tratan de un asunto -como la protección de los homosexuales- los estados pueden hacerlo si quieren.
} 
al interior de las fuerzas armadas, llamada Don't Ask, Don't Tell12. Esta política, creada en los años noventa bajo el gobierno del Presidente Bill Clinton, fue considerada un avance, porque significaba que los soldados homosexuales podrían ser parte de las fuerzas armadas si no decían nada sobre su orientación sexual. La opinión pública ha cambiado tanto en Estados Unidos, y la insensatez de dicha política era tan evidente, que el Presidente Obama la abolió en el 201113. También a nivel federal, nos encontramos con la ley de Defensa del Matrimonio (Defense of Marriage Act, en adelante, DOMA) ${ }^{14}$. La sentencia de U.S. v. Windsor dice relación, precisamente, con una objeción a la tercera parte de DOMA, que establecía que, las parejas casadas del mismo sexo no caben dentro de la definición de cónyuges para ninguna interpretación de las leyes federales ${ }^{15}$. Eso quiere decir, que esposos del mismo sexo, aun estando casados por un estado, no pueden participar de beneficios federales de ningún tipo, ni tienen los deberes que podrían pertenecer a otras personas casadas.

Al nivel estatal, hay muchas diferencias importantes en las leyes que afectan a homosexuales. En algunos estados, como California, las leyes contra la discriminación ofrecen mucha protección, como contra la discriminación en el empleo ${ }^{16}$. También permiten adopción de niños por parte de personas que se identifican como gay ${ }^{17}$. California también ofrece uniones civiles, que otorgan a las parejas del mismo sexo todos los derechos y deberes del matrimonio civil ${ }^{18}$. Este aspecto de la ley de California tuvo mucha importancia en Hollingsworth, por lo menos antes de llegar a la Corte Suprema. En doce estados y en el Distrito de Columbia, hay matrimonio civil para parejas del mismo sexo -en algunos casos, producto de decisiones de tribunales, y en otros, de modificaciones legislativas ${ }^{19}$-. En cambio,

\footnotetext{
12 "No Preguntes, No Digas" ("Don't Ask, Don't Tell”) permitió a los homosexuales servir en el servicio militar de los EE.UU., manteniendo en secreto su orientación sexual. Esta política era "la única ley federal que específicamente permitía el despido de un ciudadano americano solamente debido a su orientación sexual" ("the only federal law specifically permitting the firing of an American citizen solely because of their sexual orientation".). Hecht, Emily B. (2007). "Debating the Ban: the Past, Present and Future of Don't Ask, Don't Tell”. 244 N.J. Law. 51, 52.

13 Bumiller, Elisabeth (2011). “Obama Ends ‘Don't Ask, Don't Tell' Policy”. N. Y. Times, July 22. Disponible en: <http://www.nytimes.com/2011/07/23/us/23military.html>.

141 U.S.C. $\$ 7,110$ Stat. 2419 (1996).

${ }^{15}$ La Parte 3 de DOMA dice: "in determining the meaning of any Act of Congress or any ruling, regulation, or interpretation of the various administrative bureaus and agencies of the United States, the word 'marriage' means only a legal union between one man and one woman as husband and wife, and the word 'spouse' refers only to a person of the opposite sex who is a husband or wife".

${ }^{16}$ Cal. Gov. Code $\$ 12921$ (West 2013).

${ }^{17}$ Cal. Fam. Code $₫ 9000$ (West 2013).

${ }^{18}$ Cal. Fam. Code $\$ 297$ (West 2013).

${ }^{19}$ Quince estados, incluyendo Hawaii desde Noviembre 2013, y el Distrito de Columbia ahora permiten matrimonios del mismo sexo. Shapiro, Treena (2013). "Hawaii Becomes 15 th U.S. State to Legalize Gay
} 
en otros estados, las leyes prohíben adopción de niños por homosexuales ${ }^{20}$, no ofrecen ninguna forma de unión civil ${ }^{21}$, y varios otros tienen leyes sustantivas que prohíben el matrimonio entre personas del mismo sexo ${ }^{22}$.

\section{U.S. V. WINDSOR}

U.S. v. Windsor es la decisión más importante de las dos en análisis. En ella, la Corte decidió el caso en los méritos, mientras que en Hollingsworth declaró que no tenía jurisdicción. La demandante, Edith Windsor, se casó con su amante y pareja de muchos años, Thea Spyer, en el 2007 en Ontario, Canadá. Tuvieron que salir de los Estados Unidos para casarse, porque el estado de Nueva York, donde vivían, no reconocía el matrimonio entre personas del mismo sexo ${ }^{23}$. Después de la boda, volvieron a su casa en Nueva York, y en el 2009, Spyer murió, dejando todos sus bienes a Windsor. Spyer dejó una herencia grande, y Windsor tuvo que pagar un impuesto de herencia ascendiente a más de trescientos mil dólares. Si Windsor hubiera podido invocar una excepción fiscal, que pertenece a personas casadas, no habría tenido que pagar impuestos por la herencia de su cónyuge.

Pero Windsor no podía utilizar la excepción fiscal, ya que en virtud de la tercera sección de $\mathrm{DOMA}^{24}$, su matrimonio no estaba contemplado dentro de la definición de "cónyuges". Windsor debió pagar el impuesto, pero inició una acción para recuperar el dinero, argumentando que la tercera sección de DOMA constituía una violación de la Quinta Enmienda (Fifth Amendment) de la Constitución, la cual dice "Ninguna persona puede ser privada de la vida, la libertad o la propiedad

Marriage". Reuters, November 13. Disponible en: <http://www.reuters.com/article/email/idUSBRE9AC15U20131114>.

${ }^{20}$ Florida prohíbe que los homosexuales adopten. Fla. Stat. Ann. \$63.042 (West 2013). Mississippi prohíbe que parejas del mismo sexo adopten. Miss. Code Ann. \$93.17.3 (West 2013). Utah no permite a las parejas que cohabitan sin estar casados adoptar. Matrimonios del mismo sexo son ilegales en Utah. Utah Code Ann. $\$ 78$ B-6-117 and $\$ 30-1-4.1$ (West 2013).

${ }^{21}$ Aunque veinte estados y el Distrito de Columbia ofrecen beneficios para parejas del mismo sexo, queda aún una mayoría de estados sin proveer ningún reconocimiento. Frosch, Dan (2013). "Colorado Legalizes Civil Unions for Same-Sex Couples”. N.Y. Times, March 12. Disponible en: <http://www.nytimes. com/2013/03/13/us/colorado-legalizes-civil-unions-for-same-sex-couples.html>.

${ }^{22}$ Los estados de Pennsylvania, Tennessee, Arkansas, Alaska, Arizona, Georgia y Texas, entre otros, declaran inválido los matrimonios de parejas del mismo sexo. 23 Pa. Cons. Stat. Ann. \$1704 (West 2013), Tenn Code Ann. \$36.3.113 (West 2013), A.C.A. \$9-11-109 (West 2013), Alaska Stat. \$25.05.013 (West 2013), A.R.S. $\$ 25-125$ (West 2013), O.C.G.A. $\$ 19-3-3.1$ (West 2013), Tex. Fam. Code $\$ 6.204$ (West 2013).

${ }^{23} \mathrm{New}$ York legalizó el matrimonio entre personas del mismo sexo en el 2011. N.Y. Domestic Relations Law $\$ 10$-a (McKinney 2013). En el 2008, bajo la decisión del Tribunal de Apelación en el caso de Martínez v. County of Monroe, New York reconoció los matrimonios de parejas del mismo sexo casados en estados que lo permiten antes de legalizar estos matrimonios en New York. LipTAK, Adam (2008). "Fighting Same-Sex Policy Seems to be Uphill Battle". N.Y. Times, May 30. Disponible en: <http://www.nytimes. com/2008/05/30/nyregion/30legal.html>.

${ }^{24}$ Véase n. 15, supra. 
sin el debido proceso de la ley"25. Efectivamente, Windsor decía que esta Enmienda incluye una garantía de igualdad ante la ley (equal protection) y que DOMA le había quitado esta protección. Por lo tanto, esta parte de DOMA contradice la Constitución, y debe ser derogada.

Cuando el litigio llegó al Tribunal Federal de primera instancia, el Departamento de Justicia de los Estados Unidos informó a la Cámara de Diputados, que no quiso defender la constitucionalidad de la tercera sección de DOMA. Efectivamente, esta decisión constituyó un cambio de posición del gobierno federal. El Departamento de Justicia dio la opción a los Diputados de defender DOMA, y ellos intervinieron en el litigio ${ }^{26}$. El tribunal de primera instancia decidió que la tercera sección está en contra de la Constitución y ordenó al gobierno devolver el dinero. El gobierno no lo hizo. El tribunal de apelación confirmó la orden del tribunal de primera instancia ${ }^{27}$. Mientras tanto, ambas partes pidieron a la Corte Suprema que aceptara el caso $^{28}$, y lo hizo.

$\mathrm{Al}$ analizar los fallos de la Corte, es menester considerar la opinión de la mayoría de los ministros, y las de los disidentes ${ }^{29}$. En Windsor, el Ministro Anthony Kennedy escribió la decisión por la mayoría del tribunal, voto que compartió con Ginsburg, Breyer, Sotomayor, y Kagan. Estos cuatro últimos son los ministros más liberales, mientras que Kennedy es bastante conservador. En ocasiones vota con los liberales y en otras con la parte más conservadora, por lo que es considerado como el ministro clave a la hora de resolver un caso. Kennedy también es el ministro redactor de los fallos más importantes en el desarrollo de la jurisprudencia de igualdad hacia parejas del mismo sexo ${ }^{30}$.

Dos fallos en particular crearon la base para la opinión en Windsor, y son importantes de mencionar, aunque no tratan del matrimonio ${ }^{31}$. En Romer v. Evans ${ }^{32}$,

${ }^{25}$ U.S. Const. amend. V. "No person ... shall be deprived of life, liberty, or property without due process of law".

${ }^{26}$ Fed. R. Civ.Proc.24(a)(2) permite intervención de una parte interesada. La Casa de Diputados dio el poder de litigar el pleito a un subgrupo: BLAG (Bipartisan Legal Advisory Group). H.Res.5, 113th Cong., 1st Sess., $\$ 4(\mathrm{a})(1)(\mathrm{B})(2013)$.

${ }^{27}$ Windsor v. United States, 699 F.3d 169 (2d. Cir. 2012), rev'd 133 S. Ct. 2675 (2013).

${ }^{28}$ La gran mayoría de los casos en el Tribunal están escogidos por el Tribunal por auto de certiorari.

${ }^{29}$ Hay nueve ministros en el Tribunal. Se necesita cinco votos a favor de una sentencia para obtener una mayoría y el ministro que escribe la opinión del Tribunal trabaja con los otros ministros para preparar una opinión que comunica su razonamiento. El razonamiento es casi tan importante como la sentencia en sí porque en un sistema consuetudinario, otros tribunales usarán el razonamiento en litigios posteriores. Como el Tribunal es muy dividido, los ministros disidentes podrían ser parte de la mayoría la próxima vez que el Tribunal acepte un litigio que trate del mismo asunto. Por eso, los abogados quieren entender el razonamiento de los disidentes junto con el razonamiento de la mayoría.

${ }^{30}$ Véase Levine, Lawrence C. (2013). “Justice Kennedy's “Gay Agenda”: Romer, Lawrence, and the Struggle for Marriage Equality”. 44 McGeorge L.Rev. 1.

${ }^{31}$ En nuestro sistema consuetudinario, la jurisprudencia de estas opiniones forma la base para lo que sigue.

${ }^{32}$ Romer v. Evans, 517 U.S. 620 (1996). 
el Ministro Kennedy y otros cinco ministros decidieron que la Segunda Reforma (Amendment 2) del estado de Colorado estaba contra la Constitución de los Estados Unidos. Una mayoría de los votantes en dicho estado había aprobado una ley que buscaba derogar las leyes del estado y de los condados que protegían a gays, lesbianas, o bisexuales de discriminación en el empleo o alojamiento. Además, la misma ley prohibía que la legislatura aprobara tales protecciones en el futuro sin una consulta popular ${ }^{33}$. Como redactor del voto de mayoría, Kennedy colocó el caso dentro del marco de la jurisprudencia de derechos civiles ${ }^{34}$. Consideró la Segunda Reforma como un esfuerzo para excluir un grupo, identificado por una sola característica, de la protección de la ley. Señaló que tendría que ser el producto de cierto animus contra gays y lesbianas ${ }^{35}$ y esa fue la razón por la cual fue declarada inconstitucional. Concluyó diciendo, simplemente, que "un estado no puede dejar a un grupo de sus ciudadanos fuera de sus leyes" 36 .

En 2003, en Lawrence v. Texas ${ }^{37}$, el Ministro Kennedy, otra vez escribiendo el voto de mayoría, hizo algo que ocurre muy poco en el derecho consuetudinario: señaló que la decisión del Tribunal en Bowers $v$. Hardwick ${ }^{38}$ fue incorrecta cuando la decidieron en 1986, se siguió aplicando incorrectamente en 2003, y que su existencia como precedente "menosprecia la vida de las personas homosexuales" 39. En el sistema legal estadounidense, los ministros suelen distinguir precedentes o casos con que no están de acuerdo; pero anular el precedente es poco común. En Bowers, la Corte (en fallo redactado por el Ministro White) había decidido que la ley penal de Texas contra la sodomía entre personas del mismo sexo (y sólo entre estas personas) era constitucional ${ }^{40}$. El Ministro Burger, en su opinión concurrente,

\footnotetext{
${ }^{33}$ Amendment 2 señalaba: "No Protected Status Based on Homosexual, Lesbian, or Bisexual Orientation. Neither the State of Colorado, through any of its branches or departments, nor any of its agencies, political subdivisons, municipalities or school districts, shall enact, adopt or enforce any statue, regulation, ordinance or policy whereby homosexual, lesbian or bisexual orientation, conduct, practices or relationships shall constitute or otherwise be the basis of or entitle any person or class of persons to have or claim any minority status, quota preferences, protected status or claim of discrimination. This section of the Constitution shall be self-executing".

${ }^{34}$ Se refiere a una opinión disidente muy importante en Plessy v. Ferguson, 163 U.S. 537 (1896), donde el Ministro Harlan se opuso a una decisión del Tribunal que dijo, en el contexto de discriminación, que era constitucional separar a las razas.

35 Eso quiere decir que el motivo de excluir a los casados del mismo sexo era malo-odio, desprecio, u otra razón impermisible.

36 "[a] State cannot deem a class of citizens a stranger to its laws". Romer v. Evans, 517 U.S. 620, 635 1996).

${ }^{37}$ Lawrence v. Texas, 539 U.S. 558 (2003).

38 Bowers v. Hardwick, 478 U.S. 186; 106 S. Ct. 2841 (1986).

39 "Demeans the lives of homosexual persons". Lawrence v. Texas, 539 U.S. 558, 575 (2003).

${ }^{40} \mathrm{El}$ Tribunal dijo que no hay un derecho fundamental de tener este tipo de relación y que sería difícil proteger la sodomía consensual a la vez que permitimos procedimientos como el adulterio, el incesto, y otros crímenes sexuales. Bowers, 478 U.S. at 196.
} 
lo explicó en términos morales, refiriéndose a crímenes contra la naturaleza y la historia de leyes penales durante la época de Blackstone ${ }^{41}$. En cambio, en Lawrence, el Ministro Kennedy humaniza a la población gay y lesbiana, y con un enfoque en la libertad de tener relaciones sexuales de su preferencia, la Corte decidió que Texas no podía hacer de esta conducta un crimen ${ }^{42}$. El fallo de Lawrence, que rechaza la idea de que las relaciones sexuales consensuales entre parejas del mismo sexo puedan ser crímenes, y la caracterización de estas relaciones como expresión de la sexualidad de la pareja, abrió la puerta a litigios contra leyes como DOMA, que pretendían prevenir la aprobación de matrimonios de parejas del mismo sexo.

Volviendo a Windsor, el Ministro Kennedy destacó varias razones dentro de la sentencia. Una de ellas es el federalismo. En el sistema de los Estados Unidos, el federalismo refiere a la división de poder entre el gobierno central y los gobiernos de los estados. ${ }^{43}$ En esta división, hay ciertos asuntos gubernamentales que pertenecen en gran parte a los estados -incluso las relaciones matrimoniales- ${ }^{44}$. A pesar de que cada estado tiene el poder de decidir quién puede casarse y bajo qué condiciones, y que Nueva York había aprobado el matrimonio entre personas del mismo sexo en 2011, la ley federal no respetaba la autonomía de los estados y el deseo, expresado por medio de sus leyes, de dar dignidad al matrimonio entre personas del mismo sexo ${ }^{45}$. Además, el Congreso de los Estados Unidos había decidido que los matrimonios legales de personas del mismo sexo no merecían el mismo respeto, o los mismos beneficios, del matrimonio legal entre una mujer y un hombre. Hay más de mil leyes donde la definición de matrimonio de la tercera sección de DOMA marcaría una diferencia importante, muchas veces causando daño a la pareja del mismo sexo, o a su familia -ya sea daño patrimonial o en su dignidad-46. La Corte concluyó que la tercera sección de DOMA estaba en conflicto con las garantías de igualdad ante la ley (equal protection) y el debido proceso (due process), y por lo tanto, la declaró inconstitucional. En el último párrafo, el Ministro Kennedy señaló:

${ }^{41} I d$. at 197. El juez William Blackstone era un destacado juez y político inglés y el "autor del libro de leyes más influyente en la historia anglo-americana”, Comentarios sobre las Leyes de Inglaterra. Este tratado recopila la ley inglesa basada mayormente en la idea que la ley natural inculca en toda la gente ciertos derechos morales. Alschuler, Albert (1996-1997). "Rediscovering Blackstone". 145 U. Pa. L. Rev. 1, 2.

${ }^{42} \mathrm{El}$ Ministro Scalia, en su opinión disidente, insistió que Bowers estaba correcto, y, en lenguaje muy bruto dijo, "State laws against bigamy, same sex marriage, adult incest, prostitution, masturbation, adultery, fornication, bestiality and obscenity are likewise sustainable only in light of Bowers validation of laws based on moral choices". Lawrence, 539 U.S. at 590.

43 Wex Legal Dictionary and Encylopedia, Legal Information Institute. Disponible en: <http://www.law. cornell.edu/wex/federalism>.

${ }^{44}$ Los estados pueden decidir, por ejemplo, la edad mínima para casarse, o si primos pueden casarse. Windsor, 133 S. Ct. at 2691-2692.

45 Id. at 2692.

${ }^{46} \mathrm{Id}$. at $2694-2695$. 
"La Ley de defensa del matrimonio selecciona a un tipo de personas, consideradas por el Estado con derecho a reconocimiento y protección para mejorar su propia libertad. Impone una inhabilidad a un grupo, por la vía de negarse a reconocer un estatus que el Estado declara digno y correcto. La Ley de defensa del matrimonio transmite a todos los funcionarios federales, y ciertamente a todas las personas que se relacionan con parejas del mismo sexo, incluso sus propios hijos, la idea de que sus matrimonios son menos valiosos que los de los demás. El estatuto federal es inválido, porque no hay un propósito legitimo que justifique menospreciar y perjudicar a quienes el Estado, a través de sus leyes matrimoniales, ha buscado proteger en personalidad y dignidad. Buscando desplazar esta protección, y tratando a estas personas casadas con menos respeto que a otras, el estatuto federal viola la Quinta Enmienda. Esta opinión y sus fundamentos están limitados a los matrimonios legalmente celebrados" 47 .

Se ve claramente el mismo razonamiento que Kennedy desarrolló en Romer: que un gobierno (sea del estado o federal) no puede hacer leyes que excluyan a un grupo de personas; que los deje fuera de la protección que se entrega a los demás. La tercera sección de DOMA hizo precisamente esto: dar a entender a todos, incluso a los hijos de la pareja, que su matrimonio era de segunda clase.

Los ministros disidentes (Scalia, Roberts, Thomas, Alito) escribieron tres opiniones, donde expresaron varios puntos de vista sobre la mejor manera de analizar el caso, pero estaban de acuerdo en que la tercera sección era constitucional. ¿Cómo podría ser inconstitucional aprobar una ley como DOMA, cuando en 1996 no había ningún país en el mundo, ni un estado en los Estados Unidos, donde se permitiera el matrimonio entre personas del mismo sexo? ${ }^{48}$ Scalia predijo que a pesar de la última frase de la sentencia, que limita el fallo a matrimonios legalmente celebrados $^{49}$, la lógica usada por Kennedy ha abierto la puerta a litigios con estados que mantienen sus propios “mini-DOMAS”, que excluyen a los homosexuales del matrimonio ${ }^{50}$.

La sentencia en Windsor y la redacción de Kennedy en el voto de mayoría de la Corte es sin duda una victoria muy importante para los que favorecen la igualdad del matrimonio para todos, aunque no cambie las leyes de los estados. Scalia tiene razón en pronosticar que, a pesar de los límites de Windsor, habrá litigios contra los estados que excluyen el matrimonio entre personas del mismo sexo. De hecho, la Unión Americana de Libertades Civiles ${ }^{51}$ empezó el pasado 10 de julio

\footnotetext{
${ }^{47} I d$. at 2695-2696. Traducción del editor.

${ }^{48}$ Windsor, 133 S. Ct. at 2696.

${ }^{49} \mathrm{Id}$. at 2696. La sentencia simplemente significa que el gobierno federal no puede continuar la política que la tercera sección de DOMA había exigido - de rechazar los matrimonios entre parejas del mismo sexo reconocidos por los estados-. Los estados mantienen el derecho de no permitir el matrimonio entre homosexuales.

50 Id. at 2675 .

${ }^{51}$ American Civil Liberties Union (ACLU).
} 
un litigio contra el estado de Pennsylvania en representación de una pareja del mismo sexo, Deb y Susan Whitewood, que quieren contraer matrimonio. Ellas, que son pareja hace veintidós años y tienen dos hijas, quieren cambiar la ley del estado para la dignidad y estatus de su familia ${ }^{52}$. También habrá litigios en que se discutirá quiénes pueden hacer uso de los beneficios federales, algo que Scalia también predijo ${ }^{53}$. Por ejemplo, los estados de Texas, Georgia, Louisiana, Mississippi, Oklahoma, y West Virginia han rehusado cumplir con una orden que dispone que las parejas del mismo sexo miembros de la Guardia Nacional (National Guard) reciban los mismos beneficios federales que las parejas heterosexuales. Argumentan que como son agencias estatales, no es menester cumplir con la ley federal, y que los estados donde quedan las bases no reconocen el matrimonio entre parejas del mismo sexo ${ }^{54}$.

\section{Hollingsworth V. Perry}

La historia de este caso es un laberinto en el que no se puede encontrar la salida. Sin embargo, es importante contarla, porque hay que saber la historia de los procedimientos anteriores para entender la decisión de la Corte Suprema.

Los votantes de California, en el año 2000, promulgaron por voto popular una ley que revisó el Código de Derecho de Familia y estableció que "solo el matrimonio entre un hombre y una mujer es válido o reconocido en California" 55 , estableciendo un "mini-DOMA"56. En febrero de 2004, el alcalde de San Francisco, una de las ciudades más liberales de California, decidió rechazar la ley estatal, y ordenó que los funcionarios de la ciudad emitieran licencias de matrimonio a parejas del mismo sexo. Con ello se inició una batalla judicial, en que la Corte Suprema de California falló señalando que el alcalde no tenía el poder para contradecir la ley ${ }^{57}$, y los matrimonios terminaron. Al poco tiempo, otro litigio llegó ante la Corte Supre-

\footnotetext{
52 Gabriel, Trip (2013). “A.C.L.U. Sues Pennsylvania Over Ban on Gay Marriage”. N.Y. Times, July 9. Disponible en: <http://www.nytimes.com/2013/07/10/us/aclu-lawsuit-aims-to-overturn-pennsylvaniasban-on-gay-marriage.html>.

53133 S. Ct. at 2698; Stolberg, Sheryl Gay (2013). "After Rulings, Same-Sex Couples Grapple With Diverging State Laws”. N.Y. Times, June 28. Disponible en: <http://www.nytimes.com/2013/06/29/us/ after-rulings-same-sex-couples-grapple-with-diverging-state-laws.html>.

${ }^{54}$ Oppel, Richard A., Jr. (2013). “Texas and 5 Other States Resist Processing Benefits for Gay Couples”. N.Y. Times, November 11. Disponible en: <http://www.nytimes.com/2013/11/11/us/texas-and-5-other-statesresist-processing-benefits-for-gay-couples.html?ref=opinion>; Oppel, Richard A., Jr. (2013). "Resistance to Marriage Equality". N.Y. Times, Editorial Board, November 13. Disponible en: <http://www.nytimes. com/2013/11/14/opinion/resistance-to-marriage-equality.html?emc=eta1>.

$55 \mathrm{Cal}$. Fam. Code $\$$ 308.5. "Only marriage between a man and a woman is valid or recognized in California".

${ }^{56}$ El Estado de California (por voto popular) tenía la misma meta que el gobierno federal tenía en DOMA: asegurar que los homosexuales no pudieran utilizar las leyes del estado para contraer matrimonio.

${ }^{57}$ Lockyer v. City and County of San Francisco, 33 Cal. 4th 1055 (Cal. 2004).
} 
ma del Estado, en que los demandantes argumentaron que la ley que prohibía el matrimonio entre personas del mismo sexo no cumplía con las normas electorales de la Constitución del Estado ${ }^{58}$. La Corte Suprema de California decidió en favor de los demandantes, e inmediatamente muchas parejas del mismo sexo empezaron a casarse (unas dieciocho mil parejas, entre junio y noviembre del 200859).

En 2008, un grupo de votantes propuso una reforma a la Constitución del Estado, y usando un proceso de democracia directa ${ }^{60}$, sometieron a votación la llamada Propuesta 8 para volver a establecer la misma prohibición. Los proponentes querían asegurarse de que ni el alcalde ni el poder legislativo del Estado pudieran pasar por alto la prohibición de matrimonios entre parejas del mismo sexo, con la idea de que, al estar la prohibición en la Constitución del Estado, fuera muy difícil de deshacer. Una mayoría de los votantes aprobaron la Propuesta $8^{61}$. Los oponentes de la enmienda trataron de invalidarla, pero la Corte Suprema de California decidió que era válida ${ }^{62}$. A pesar de ello, la Corte no anuló los matrimonios ya cumplidos, pero prohibió que se siguieran celebrando.

Los abogados de las organizaciones pro igualdad verdaderamente no sabían que hacer. La única vía de apelación posible era ante los tribunales federales, demandando la incompatibilidad de la Propuesta 8 con la Constitución de los Estados Unidos por negar la igualdad ante la ley. Sin embargo, no existía jurisprudencia a favor de un derecho constitucional que garantizara el matrimonio entre parejas del mismo sexo, y con una Corte Suprema integrada por cinco ministros bastante conservadores, existía el riesgo de obtener un fallo adverso, que dañara aún más la igualdad. Sin embargo, dos parejas decidieron iniciar un litigio ante el Tribunal Federal, donde presentaron las cuestiones constitucionales, demandando al gobierno, al procurador general y a otros funcionarios del Estado de California.

Aunque hasta este punto el gobierno del estado había defendido la legalidad de la Propuesta 8, las elecciones estatales cambiaron el panorama político, ya que resultaron electos un gobernador y procuradora del partido demócrata. A raíz de ello, el Estado de California cambió su posición y decidió no defender la constitucionalidad de la Propuesta 8. Sin embargo, sus autores intervinieron para defenderla. Se realizó un proceso que duró doce días, durante el cual el tribunal federal

\footnotetext{
58 In re Marriage Cases, 43 Cal. 4th 757 (Cal. 2008).

${ }^{59}$ McKinley, Jesse (2009). "California Couples Await Gay Marriage Ruling”. N.Y. Times, May 25. Disponible en: <http://www.nytimes.com/2009/05/26/us/26gay.html>.

${ }^{60}$ Hollingsworth, 133 S. Ct. 2652. Para poner una enmienda constitucional en la balota en California, es necesario que la petición obtenga cierta cantidad de firmas, equivalentes al $8 \%$ del total de votos para Gobernador en la última elección gubernativa (807,615 firmas). Cal. Const., Art. II, $\$ 8$ (b); Elections Code $\$ 9035$.

${ }^{61}$ La Proposición 8 paso con una votación del 52\% a favor, y el 48\% en contra de esta. ArChibold, Randal C. and Goodnough, Abby (2008). "California Voters Ban Gay Marriage". N.Y. Times, November 6. Disponible en: <http://www.nytimes.com/2008/11/06/us/politics/06ballot.html>.

62 Strauss v. Horton, 46 Cal. 4th 364 (Cal. 2009).
} 
de primera instancia recibió pruebas de ambas partes. Los autores de la Propuesta 8 intentaron establecer que existen diferencias entre las parejas homosexuales y heterosexuales que justifican tratarles de manera distinta con respeto al matrimonio. Las pruebas que presentaron, correspondieron a sus argumentos principales: que la tradición justifica la diferencia; que los tribunales deben proceder lentamente en llevar a cabo cambios sociales muy grandes; que las parejas del sexo opuesto son mejores padres que las parejas del mismo sexo; y que el tribunal debería proteger los intereses de quienes se oponen al reconocimiento del matrimonio entre personas del mismo sexo. El juez del tribunal de primera instancia concluyó que los autores de la Propuesta 8 no lograron acreditar su defensa, y su sentencia ordenó al gobierno del Estado dejarla sin vigencia ${ }^{63}$.

El gobierno de California reafirmó su decisión de obedecer el mandato judicial, y por tanto, no quiso pedir la revisión de la sentencia ante el Tribunal de Apelación. Entonces, los autores de la Propuesta recurrieron ante el Tribunal de Apelación, para que éste anulara el fallo, el cual decidió enviar una consulta a la Corte Suprema del Estado de California. Quería saber si los autores de la Propuesta 8 tenían un interés personal y concreto en la constitucionalidad de la ley, que les diera la capacidad jurídica necesaria para continuar con el litigio ${ }^{64}$. La Corte Suprema de California respondió positivamente a la consulta ${ }^{65}$, y el Tribunal de Apelación, fiándose de la opinión de la Corte Suprema del Estado, decidió el litigio en los méritos, confirmando la sentencia del tribunal de primera instancia. Las partes pidieron que la Corte Suprema de los Estados Unidos aceptara conocer el caso.

Los ministros de la Corte Suprema votaron a favor de aceptar conocer de $\mathrm{Ho}$ llingsworth $v$ Perry 66 , y por lo tanto, todo el mundo esperaba una respuesta definitiva: si es o no constitucional excluir a los homosexuales del matrimonio bajo las leyes de un estado. Sin embargo, la Corte decidió que no tenía jurisdiction sobre el litigio, porque los autores de la Propuesta 8 no tenían un interés suficientemente concreto y personal para invocar la jurisdicción de la Corte. El Ministro Roberts, escribiendo por la mayoría del Tribunal señaló:

“... una vez que la Propuesta 8 fuera aprobada por los votantes, la medida se convierte en 'una enmienda constitucional debidamente promulgada o en una ley del Estado' (...) Los autores no tienen un rol-ni especial ni de otro tipo-en la aplicación de la Propuesta 8 (...) Por lo tanto, no tienen un 'interés personal' en defender su aplicación que sea distinto del interés general de los ciudadanos del Estado de California... "67.

63 Perry v. Schwarzenegger, 704 F. Supp. 2d 921, 1004 (N.D.CA 2010).

${ }^{64}$ Perry v. Schwarzenegger, Civ. No 10-16696 (C.A.9, Aug. 16, 2010).

65 Perry v. Brown, $52 \mathrm{Cal} 4^{\text {th }} 1116,1127$ (2011).

${ }^{66}$ Hollingsworth v. Perry, 133 S. Ct. 786 (Mem.) December 12, 2012.

${ }^{67}$ Hollingsworth $_{2} 133$ S. Ct. at 2663. Traducción del editor. 
El Ministro Roberts también notó que, con todo respeto a la Corte Suprema de California, un tribunal del Estado no puede decidir si un tribunal federal tiene jurisdicción o no ${ }^{68}$.

Los Ministros disidentes (Kennedy, Thomas, Alito, y Sotomayor) creían que la Corte tenía jurisdicción sobre el litigio ${ }^{69}$, pero ninguno de ellos ofreció su opinión sobre la constitucionalidad de la Propuesta 8.

Casi inmediatamente después de la sentencia de la Corte Suprema, el Tribunal de Apelación Federal quitó el aplazamiento del fallo del tribunal de primera instancia, y los matrimonios entre parejas del mismo sexo empezaron de nuevo en California ${ }^{70}$.

Entonces, ¿qué significa Hollingsworth v. Perry? Para los demandantes, y para las parejas del mismo sexo que viven en California, significa que pueden casarse y que los oponentes a la igualdad del matrimonio en California han, finalmente, perdido la batalla. Como la sentencia del tribunal de primera instancia obliga solamente a las leyes del Estado de California, ésta no tiene ningún efecto legal en otros Estados. Sin embargo, el hecho de que un tribunal federal haya dicho que no hay justificación para sostener una diferencia en la ley de matrimonio entre homosexuales y heterosexuales entrega confianza, y podría animar a parejas gay en otros estados que prohíben el matrimonio a intentar mociones similares. El resultado de los litigios en estos estados dependerá completamente de cómo opere la ley en ese territorio determinado y de los jueces. La igualdad ante la ley en el matrimonio sigue siendo un tema polémico en los Estados Unidos.

Por ahora, la Corte Suprema del país ha evitado la necesidad de resolver las cuestiones constitucionales previniendo de las leyes estatales que prohíben el matrimonio entre parejas del mismo sexo. Hay mucha gente que piensa que la Corte ha actuado bien, ya que a pesar de su sentencia rehusando jurisdicción, dejó intacta la sentencia del tribunal de primera instancia que concluyó que la Propuesta 8 era inconstitucional. La opinión del juez de primera instancia no podría ser más clara en rechazar los argumentos de quienes se oponen a la igualdad en el matrimonio. Los ministros de la Corte Suprema sabían que se reanudarían los matrimonios entre parejas del mismo sexo en California, un estado que influye mucho en la política de los Estados Unidos. De esta manera, Hollingsworth ha provocado cambios, pero solamente en un estado. Los otros pueden analizar sus propias leyes de nuevo, y algunos decidirán en favor de la igualdad. Otros van a mantener sus "mini-Domas" y a lo mejor, en el futuro la Corte Suprema se enfrentará a otro caso, donde no podrá evitar tomar una decisión.

${ }^{68} I d$. at 2667.

${ }^{69} \mathrm{Id}$. at 2668.

70 LiptaK, Adam (2013). "Supreme Court Bolsters Gay Marriage with Two Major Rulings". N.Y. Times, June 26. Disponible en: <http://www.nytimes.com/2013/06/27/us/politics/supreme-court-gay-marriage. html>. 


\section{CONCLUSIÓN}

U.S. v. Windsor y Hollingsworth v. Perry son sentencias muy importantes. En pocos meses, U.S. v. Windsor ha puesto en marcha a muchos departamentos del gobierno federal. De esta manera, el gobierno federal se convertirá en un ejemplo para los estados de cómo se puede actuar en este período de transición ${ }^{71}$. Hollingsworth deja intacta una opinión del tribunal de primera instancia que repite el caso de Romer, esta vez en el contexto del matrimonio, concluyendo que un estado no puede aislar a un grupo de sus ciudadanos y quitarles los derechos que reciben los demás. Aunque la Corte Suprema no lo dijo, es un mensaje fuerte, que ha creado un ambiente mucho más abierto y positivo para la comunidad gay.

\footnotetext{
${ }^{71}$ El Pentágono acaba de anunciar que su nueva política es tratar en forma igualitaria a todos los miembros de las fuerzas armadas. Empezando el 3 de septiembre, miembros que se identifican como gay o lesbiana pueden pedir permiso por un máximo de siete días para casarse si la base está a más de cien millas de un estado donde pueden contraer matrimonio. Cloud, David S. (2013). "Sacramento Bee”. August 15, 2013, at A8. También el Departamento de la Hacienda (Internal Revenue Service) anunció que va a reconocer a todas las parejas casadas, aún si el estado donde viven no reconoce su matrimonio. Gay Marriages Get Recognition from I.R.S. Disponible en: <http://www.nytimes.com/2013/08/30/us/politics/irs-to-recognizeall-gay-marriages-regardless-of-state.html>.
} 